\title{
MORAVIG: An Android Agent for the Project Mobile e- Learning Session
}

\author{
Mohammed Bousmah \\ STIC Laboratory, F.S. \\ Chouaib Doukkali University \\ El Jadida, Morocco
}

\author{
Ouidad Labouidya \\ STIC Laboratory, F.S. \\ Chouaib Doukkali University \\ El Jadida, Morocco
}

\author{
Najib El Kamoun \\ STIC Laboratory, F.S. \\ Chouaib Doukkali University \\ El Jadida, Morocco
}

\begin{abstract}
At present, Cloud Computing enables new ways to access services anywhere, at any time and using any devices (Smart phones, tablet computers, laptops, desktops...). The need of deploying distributed applications such as multi-agent systems on handheld devices is becoming more and more important in Massive Open Online Courses (MOOCs). This implementation will make mobile applications more intelligent and proactive. This paper seeks to present a technological innovation for the Project Mobile e-Learning session, called MORAVIG (MORoccan Android VIrtual Guide). This mobile agent provides assistance and help for teachers and students. Our goal is to make the process of project management accessible for them. Jade-Leap Android add-on was used to develop MORAVIG and to solve the integration of this agent in Android platform.
\end{abstract}

\section{Keywords}

Project Based Learning, MOOCs, Cloud Computing, MultiAgent System, Android-Jade.

\section{INTRODUCTION}

Recent years have seen a growing recognition and general acceptance of the Project Based Learning (PBL) in education, especially in Moroccan higher education. This approach transforms teaching from "teachers telling" to "students doing" [1]. Teachers and students are facing several challenges during a project based learning session. The biggest challenge is: What methodology should be followed for successful project?

Typically, in the world of management, we describe the process of project management as the most effective method for a successful project, but in the teaching world, there is no standard approach to a PBL session, each researcher or teacher offers his own approach.

In this article, we propose to use the project management process such us a methodology that should be followed for successful project learning session, in Massive Open Online Courses (MOOCs). Our goal is to make this process accessible for teachers and students by developing an Android assistant agent called MORAVIG (MORoccan Android مرافق VIrtual Guide); that means companion in Arabic (see figure 1).

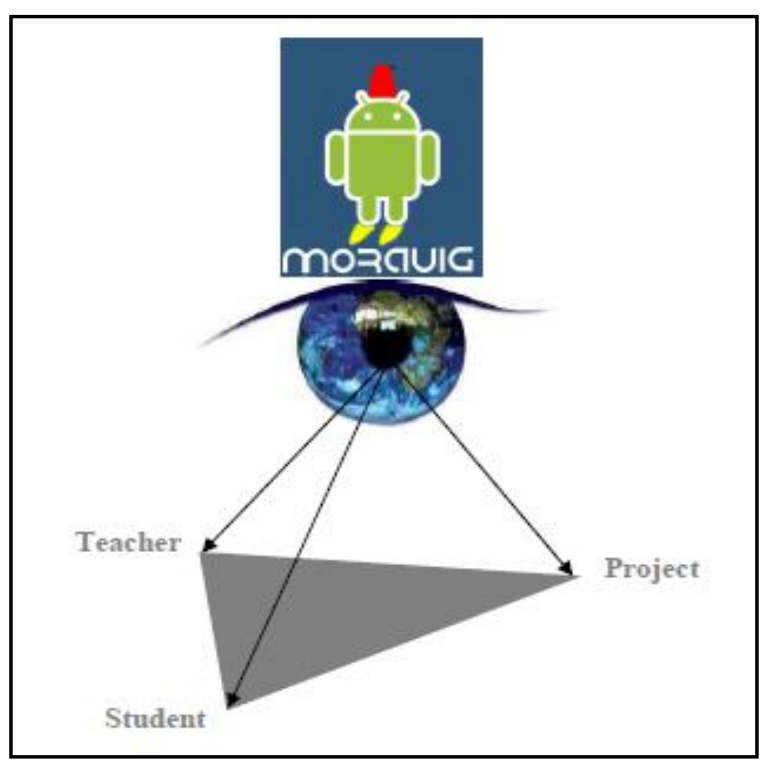

Fig 1: MORAVIG (MORoccan Android VIrtual Guide)

The need of developing a virtual guide such as MORAVIGis justified, first, by the difficulties encountered by students during the application of the project management process, and secondly [2], by the difficulty for teachers to follow and supervise multiple projects at the same time in Massive Open Online Courses (MOOCs) [3]. Therefore, MORAVIG provides the following services:

- $\quad$ Gives assistance and help for students and teachers to apply project management process in Project Mobile e-Learning (PMeL) session.

- Facilitates monitoring and supervising multiple projects by teachers at the same time in Massive Open Online Courses (MOOCs).

Our proposal revolves around three elements:

- Cloud computing must support e-learning and mobile-learning such as LaaS (Learning as a Service);

- Cloud infrastructures can offer an ideal platform for implementing Massive Open Online Courses (MOOCs);

- Multi-Agents technology is becoming more and more important in Massive Open Online Courses (MOOCs).

To developing and implementing this virtual guide, we have chosen the following technologies: The Cloud Computing and the Multi-Agent System. 
The first part of this paper introduces cloud-computing concepts, MOOCs and reviews some research activities. The second part presents the general concepts of Android Platform. The third part is devoted to the design and implementation of MORAVIG. We finish by the conclusion and the future work.

\section{CLOUD COMPUTING CONCEPT AND MOOCs}

\subsection{Cloud Computing}

The main objective of Cloud Computing is to provide software, services and computing infrastructures carried out independently by the network. It's a new paradigm of IT that can provide all resources such as software (SaaS), platform (PaaS) and infrastructure (IaaS) as a service over the Internet. In Cloud Computing, user can access the services anywhere, at any time and using any devices (Smart phones, tablet computers, laptops, desktops...).
Currently in literature, we can find several definitions for the cloud computing. According to the National Institute of Standards and Technology (NIST) [4], Cloud computing is a model for enabling convenient, on-demand network access to a shared pool of configurable computing resources (e.g., networks, servers, storage, applications, and services) that can be rapidly provisioned and released with minimal management effort or service provider interaction. This cloud model promotes availability and is composed of five essential characteristics (On-demand self-service, Broad network access, Resource pooling, Rapid elasticity, Measured Service); three service models (Cloud Software as a Service (SaaS), Cloud Platform as a Service (PaaS), Cloud Infrastructure as a Service (IaaS) (see figure 2); and, four deployment models (Private cloud, Community cloud, Public cloud, Hybrid cloud). Key enabling technologies include: (1) fast wide-area networks, (2) powerful, inexpensive server computers, and (3) high-performance virtualization for commodity hardware.

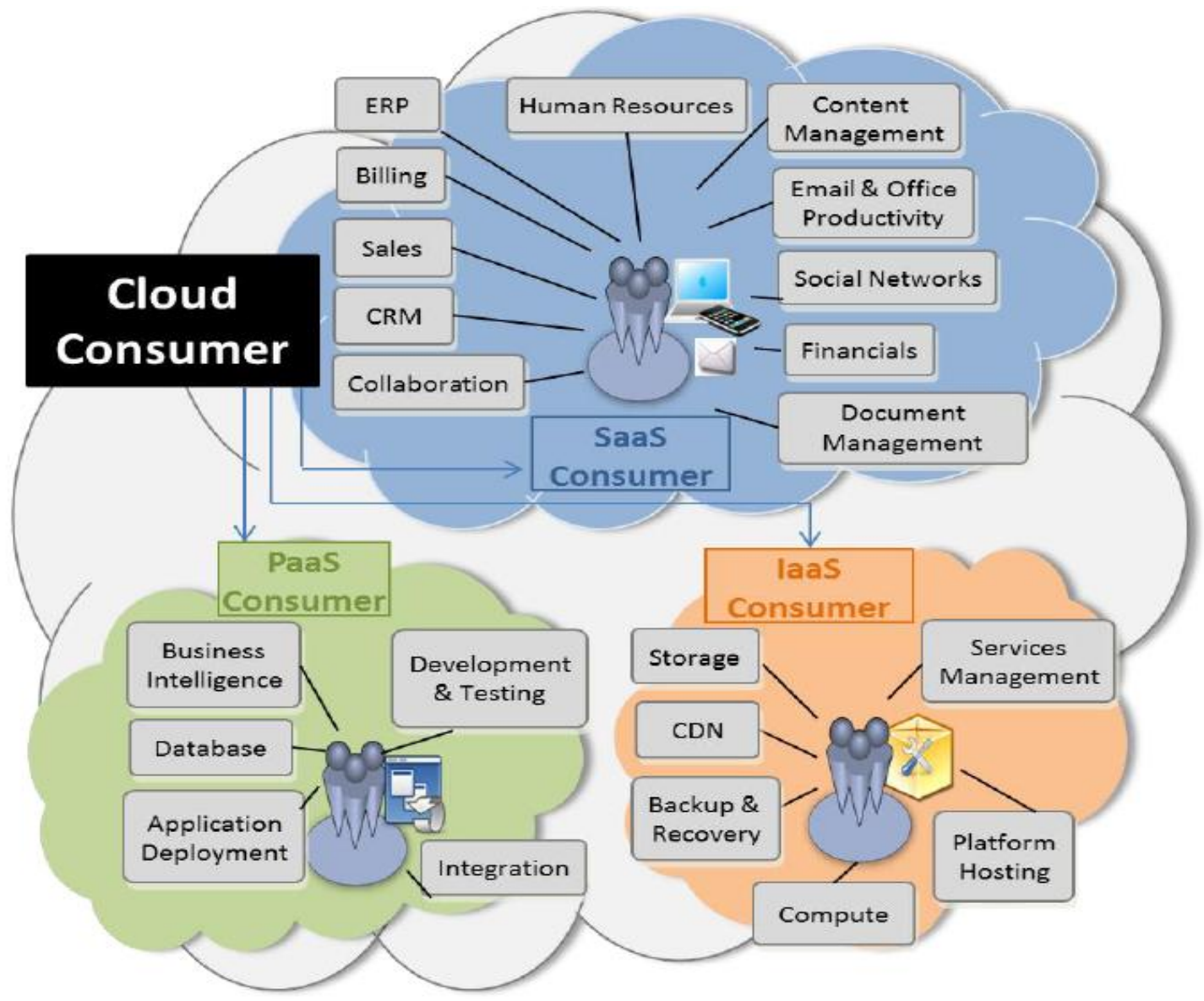

Fig 2: Example of Services Available to a Cloud Consumer [4]

In our sense, cloud computing provides many benefits for university:

- Lower capital costs - University can provide unique services using large-scale computing resources from cloud service providers, and then nimbly add or remove IT capacity to meet peak and fluctuating service demands while only paying for actual capacity used.

- Lower IT operating costs - University can rent added server space for a few hours at a time rather than maintain proprietary servers without worrying about upgrading their resources whenever a new application version is available. They also have the flexibility to host their virtual IT infrastructure in locations offering the lowest cost.

- No hardware or software installation or maintenance

- Optimized IT infrastructure provides quick access to needed computing services

- Users (teachers, students, admin, etc.) can access the services anywhere, at any time and using any devices (Smart phones, tablet computers, laptops, desktops...). 
In these advantages, many researchers of e-learning area [5] [6] [7] [8] attempt to apply their process to cloud computing. It is one of the new technology trends likely to have a significant impact on the learning environment and the Massive Open Online Courses (MOOCs) in recent years. However, the data privacy and security are the main risk [9].

\subsection{Massive Open Online Courses (MOOCs)}

In the Wikipedia, the following definition of Massive Open Online Course is provided:

"MOOC is an online course aimed at large-scale interactive participation and open access via the web. In addition to traditional course materials such as videos, readings, and problem sets, MOOCs provide interactive user forums that help build a community for the students, professors, and teaching assistants (TAs). MOOCs are a recent development in distance education."

Class Central is a specialized website on MOOC market. In its recent report of stats and trends [10] [11], Class Central offers a study of the rapid expansion of MOOC over the past three years.

As shown in figure 3, we observe a high growth in course offerings since November 2011, the cumulative number of courses started or scheduled reached 2100 in February 2015.

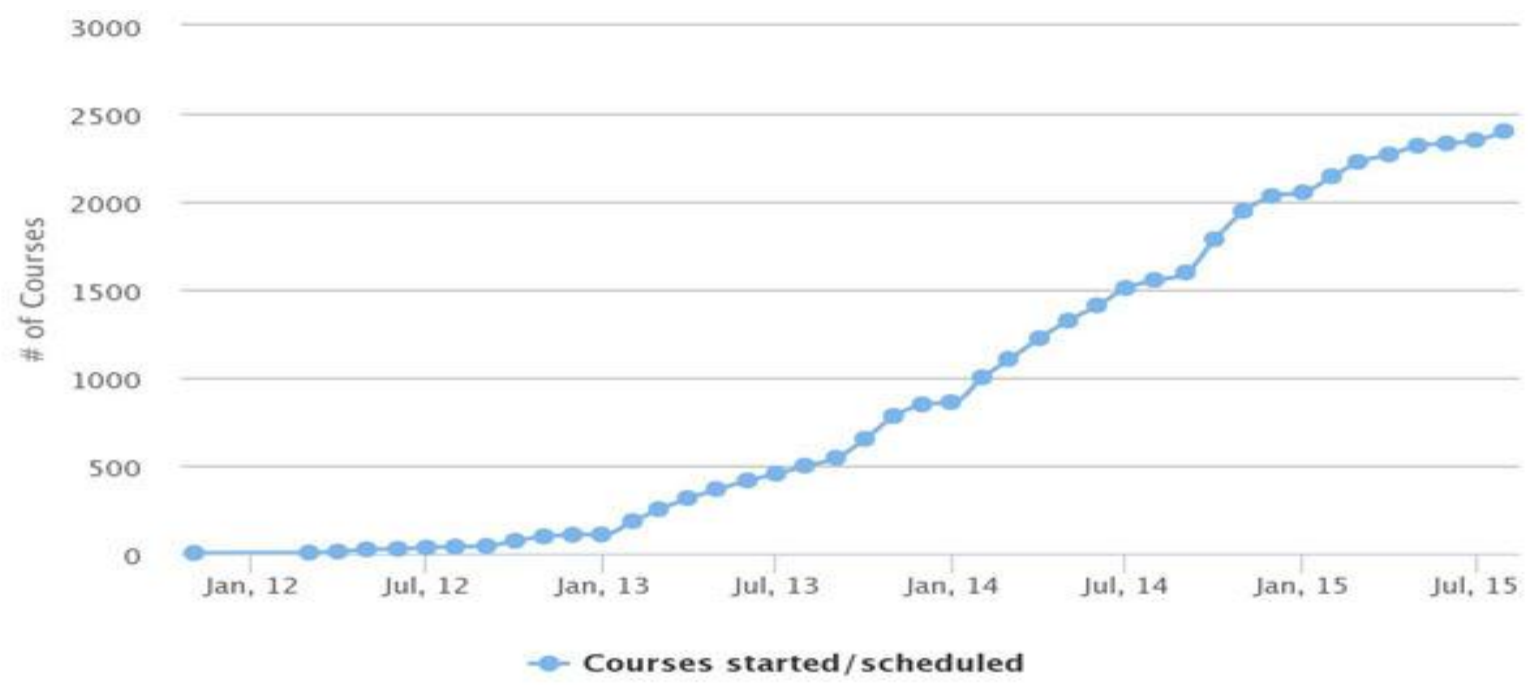

Fig 3: The cumulative number of MOOCs scheduled or started, 2011-2015 [11]

Today, almost 400 universities offering MOOCs, and according to US News \& World Report rankings [12], 22 of the top 25 US universities now offer online courses free of charge. Courses are currently offered in 13 languages, the vast majority in English (80\%), followed by Spanish (8.5\%), French (4\%) and Chinese (3.5\%). The main areas of courses are humanities, computer science and business administration. As shown in figure 4, we observe that Coursera is the market leader in MOOCs with $36 \%$ of provided courses, followed by edX with $36 \%$ of provided courses.
Table 1 presents the top five providers of MOOCs In 2014 Coursera became the first International MOOC provider to cross 11 million registered users, followed by edX and Udacity, which offered successively 3 million and 1.5 million registered students, the Spanish MiriadaX became the first non-U.S. MOOC provider to cross 1 million registered users, followed by the UK FutureLearn MOOC provider with 800 mille-registered users.

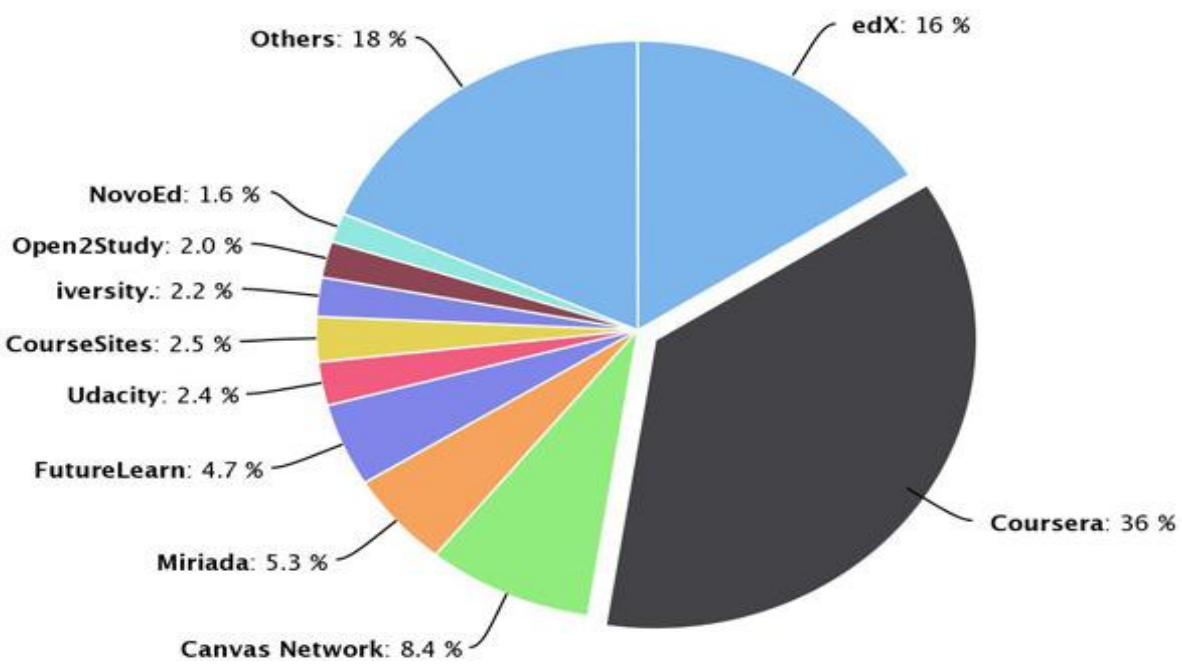

Fig 4: Course distribution by MOOC provider [11] 
Table 1. TOP five PROVIDERS [11]

\begin{tabular}{|c|c|}
\hline Provider & Registered students \\
\hline Coursera & 11 million \\
\hline edX & 3 million \\
\hline Udacity & 1.5 million \\
\hline MiriadaX & 1 million \\
\hline FutureLearn & 800.000 \\
\hline
\end{tabular}

\section{ANDROID PLATFORM}

Android is an open operating system designed for use in mobile devices such as smart phones tablets and other devices. Android system is actually owned by Google, Inc., it includes a Linux kernel (and its drivers), an abstraction layer for access to sensors, a virtual machine entitled Dalvik Virtual Machine, applications (browser, contact management, telephony application ...) and Libraries (SSL, SQLite, OpenGL ES, etc ...) (see figure 5).

Android has several advantages, as listed below [13]:

- The entire Application framework can be reused and replaced by selective components

- Dalvik virtual machine enhances the power management systems

- $\quad$ Support for 2D and 3D graphics (OpenGL ES 1.0), so lot of business for animation developers.

- Reliable and enhanced data storage ( using SQLite framework)

- Developers can create media common applications since it supports common media file formats (MPEG, MPEG3, MPEG4, H.286, AAC, AMR, JPG, PNG, GIF and more)

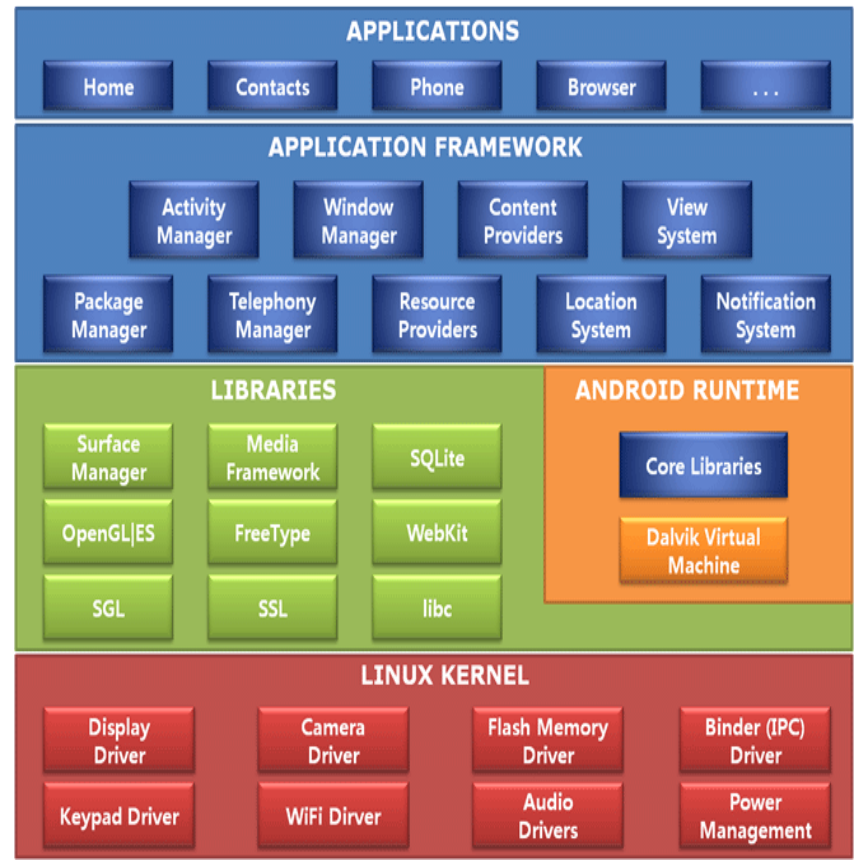

Fig 5: Android Architecture
- GSM, EDGE, 3G, 4G, HSCSD, Wi-Fi network applications support (Depends on hardware)

- Open source Web-Kit Engine-based web-browser GPS, Navigational compass, Touch-Unlock, and accelerometer applications support (Depends on hardware)

- Androids development environment includes a device emulator, debugger, performance profiling tool, and an Eclipse IDE plug-in or Android Studio IDE, more intuitive than Eclipse (which Google had previously worked), allows for easier Android apps on Windows (see figure 6).

- Multi-Agents technologies can be included in Android platform

As an open platform, Android allows users to load software from any developer onto a device. As with a home PC, the user must be aware of who is providing the software they are downloading and must decide whether they want to grant the application the capabilities it requests. This decision can be informed by the user's judgment of the software developer's trustworthiness, and where the software came from.

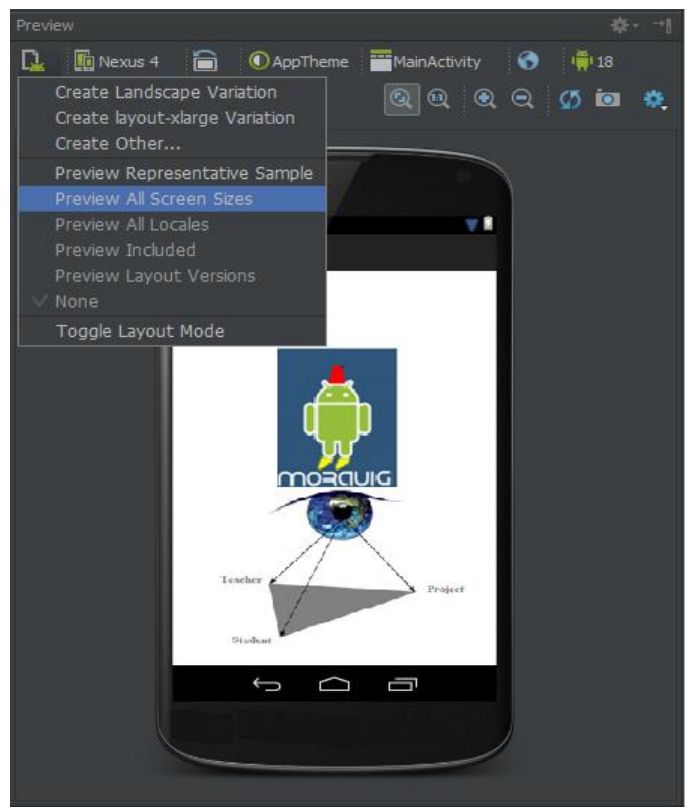

Fig 6: Android Studio IDE

\section{AN ANDROID COMPANION AGENT FOR PROJECT MANAGEMENT PROCESS}

\subsection{Project Management Process}

In our sense, Project Management Process offers a wide range of benefits to both students and teachers. In fact, according to Project Management Institute, we can define the Project Management as:

"The art of directing and coordinating human and material resources through the life of a project by using modern management techniques to achieve predetermined goals of scope, cost, time, quality and participant satisfaction".

The new edition of the PMBOK® 5th Guide was released at the end of 2013 describe, over more than 590 pages, project management processes, their inputs, their outputs and their associated tools and techniques. Fifth Edition reflects the 
collaboration and knowledge of working project managers and provides the fundamentals of project management as they apply to a wide range of projects. This internationally recognized standard gives project managers the essential tools to practice project management and deliver organizational results.

Project has a beginning and an end, it is said to have a life cycle. A number of writers have sought to define this life cycle in terms of a set of discrete phases through which the project passes. For example, Rustain and Estes [14] define a life cycle as commencing with a concept phase and concluding with a post accomplishment phase as shown in Figure 7, in which four intermediate stages are identified:

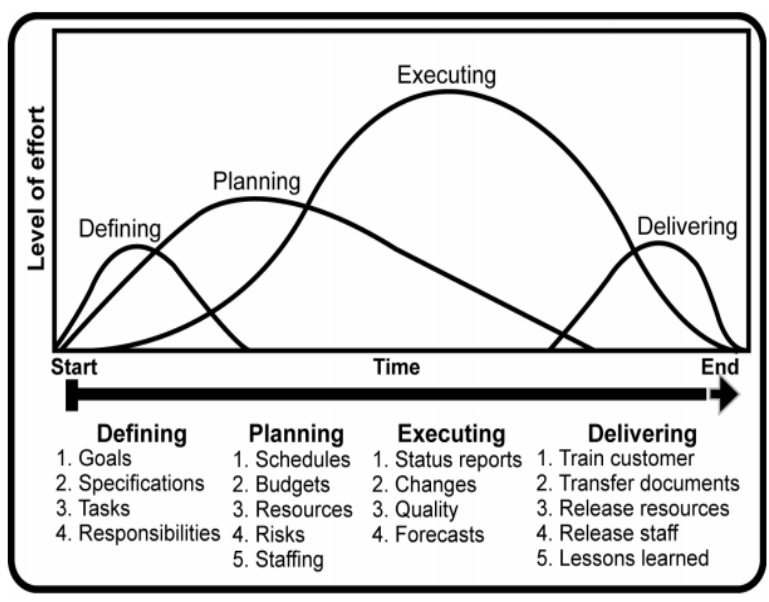

Fig 7: The Project Life Cycle [15]

Therefore, in Project-based learning session, a coherent project management strategy can:

- Increase the efficiency of developing learning project.

- Understanding the needs of stakeholders.

- Planning what needs to be done, when, by whom, and to what standards.

- Building and motivating the team.

- Coordinating the work of different people.

- Monitoring work being done.

- Managing any changes to the plan.

- Delivering successful results.

However, we have found that students and teachers in our university ignore this strategy. Our goal therefore is to make the process of project management accessible for them by developing MORAVIG: an Android companion agent for mobile learning in cloud computing.

\subsection{MORAVIG: an Android Companion Agent}

Cloud infrastructures can offer an ideal platform where run Multi-Agents System. In fact, an agent is a software entity capable of acting intelligently on behalf of a user, in order to accomplish a given task. Agents, like humans, co-operate so that a society of agents can combine their efforts to achieve a desired goal. The Multi-Agent architecture was motivated by several reasons. First, it is an open system, dynamic and complex that it is possible to add, change agents without affecting the overall structure. Secondly, the agents are a natural metaphor to model our environment. Thirdly, this approach is well adapted for highly interactive distributed system. Finally, this implementation will make mobile applications more intelligent and proactive [16]

JADE (Java Agent DEvelopment Framework) is a software framework fully implemented in Java language. It simplifies the implementation of multi-agent systems [17]. Jade-Leap add-on was used to develop MORAVIG and to solve the integration of this agent in Android platform. It is a main actor in the operating system market for mobile and embedded devices such as smart phones, tablets and other.

As shown in figure 8, we can easily integrate agent technology under Android with JADE-LEAP and JADELEAP Android.

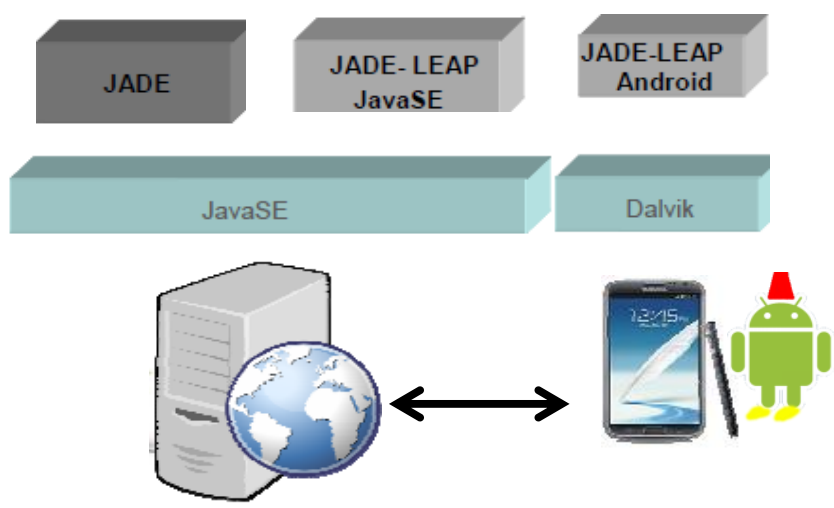

Fig 8: Overview of Android and JADE-LEAP

For specific tasks, it is very useful to have an agent platform on the mobile device itself. A prototype of the MORAVIG: the Android companion agent for mobile learning is being implemented in order to generate results that can be analyzed and validate our work. To this end, we have used the Multiagent System Engineering methodology MASE [18] and the FIPA compliant JADE platform to implement our system.

The choice of MASE is justified by:

- $\quad$ The simple, modest and pragmatic vision that MASE gives to the definition of an agent and thereafter to the system SMA that is perfectly appropriate to us.

- The automation of the "agentification" process.

- The documentation availability.

MASE divides the development process into two major phases:

- The analysis phase and the design phase. For each phase, MASE provides a set of stages need to be performed. Figure 9 presents the development process proposed by MASE. The analysis phase consists of the following stages: capturing goals, applying use cases, and refining roles.

- The design phase consists of the following stages: creating agent classes, constructing conversations, assembling agent classes, and system design.

The MAS (Multi-Agent System) specified by these methodologies are often difficult to implement directly starting from the standard programming languages like Java or others. 


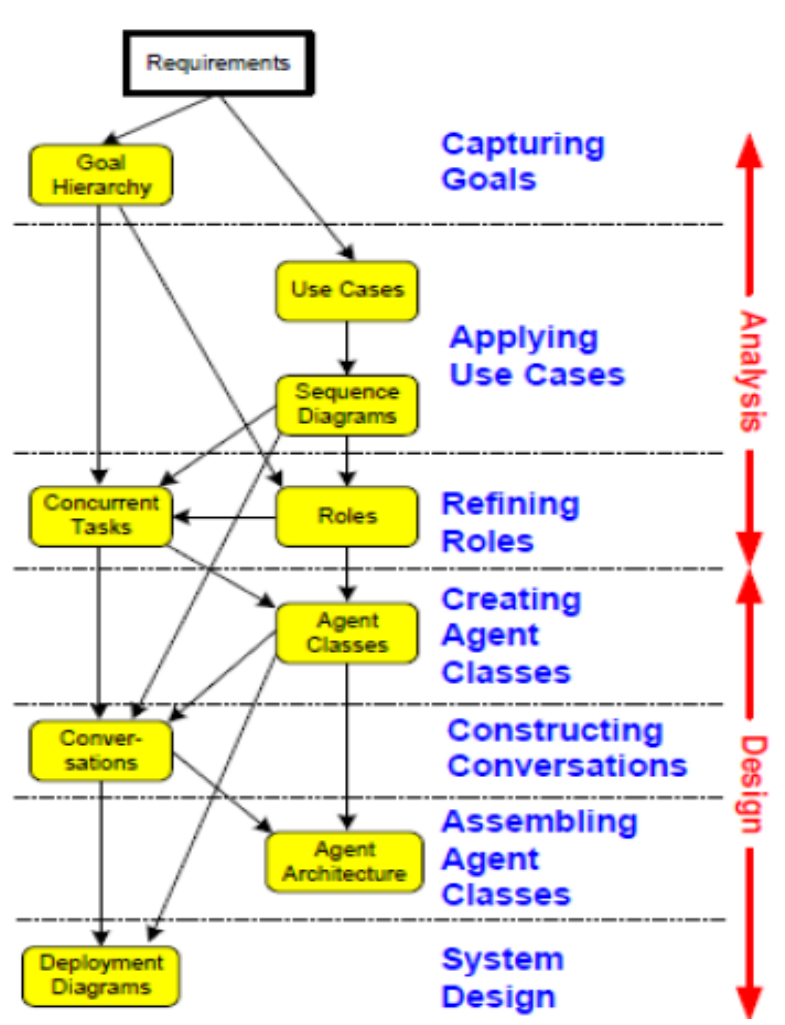

Fig 9: The MaSE development stages [18]

Several tools (software elements offering the services for the MAS development) of various types were developed recently for the programming agent-oriented like JADE [19], Zeus [20], MadKit [21], Agent Builder [22].

So, after an evaluation of these platforms, we chose JADE (Java Agent Development Framework) which is a multiagents platform developed in Java by CSELT (Group of search for Gruppo Telecom, Italy) and which facilities the construction of the multi-agents systems and the realization of applications in conformity with FIPA standard [23]. This choice was made on the basis of several reasons whose principal ones are:

- JADE is an open platform source, documented well and updated periodically.

- The platform JADE can be distributed on several hosts, in particular, smartphones and tablets. The communication inter-agents is carried out by ACL (Agent Communication Language) messages, which can be directly formulated or supervised thanks to dedicated interfaces.

- JADE offers a graphic user interface to manage several agents and multi-agents platforms; the activity of each platform can be supervised and recorded.

As depicted in Figure 10, this Android application allows participating to the assistance from an Android device. It includes an Android agent that managing the interactions with students and teachers. This Android companion agent helps them to defining, planning and executing project.

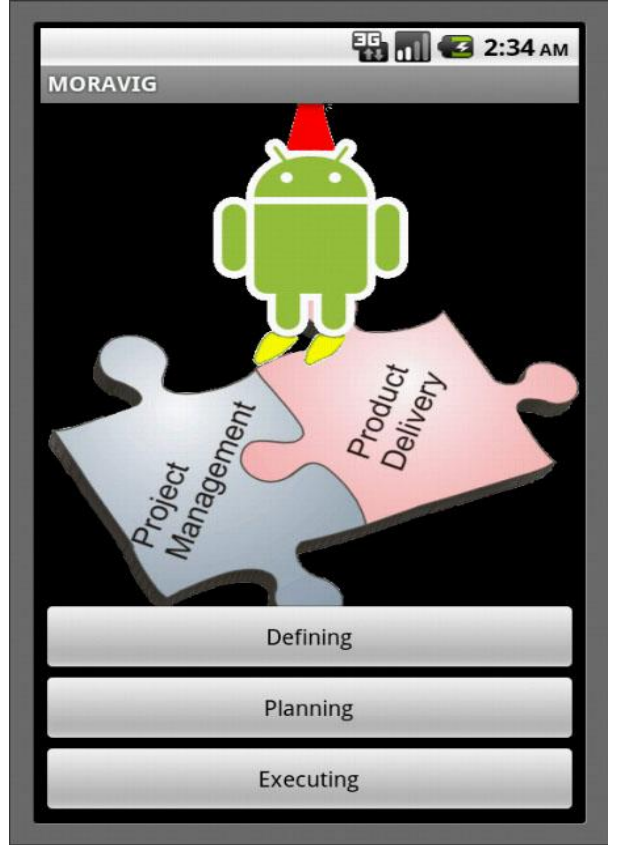

Fig 10: MORAVIG: an Android companion agent

In fact, the core components of project management with MORAVIG are: defining the reason why a project is necessary

- capturing project requirements, specifying quality of the deliverables, estimating resources and timescales

- preparing a project learning session

- developing and implementing a management plan for the project

- leading and motivating the project delivery team

- monitoring progress against plan

- maintaining communications with stakeholders and the project organization

- $\quad$ provide help and assistance during execution phase

- closing the project in a controlled fashion when appropriate.

The prototype system naturally breaks down into two subsystems: A JADE agent platform with all the service provider agents runs on the servers and JADE runtime containers where all the data collection agents are created on Android devices. A batch file (For Windows platform) or Unix script (For Linux or Mac OS X) is used for starting the JADE platform on the server. After Executing the batch or script file in the command line, a JADE agent platform will be started with all the mobile agents; entitled for example MORAVIG_S1, MORAVIG_S2, MORAVIG_S3 and MORAVIG_T1 for the three students and the teacher of a Project Mobile e-Learning (PMeL) session (see figure 11). 


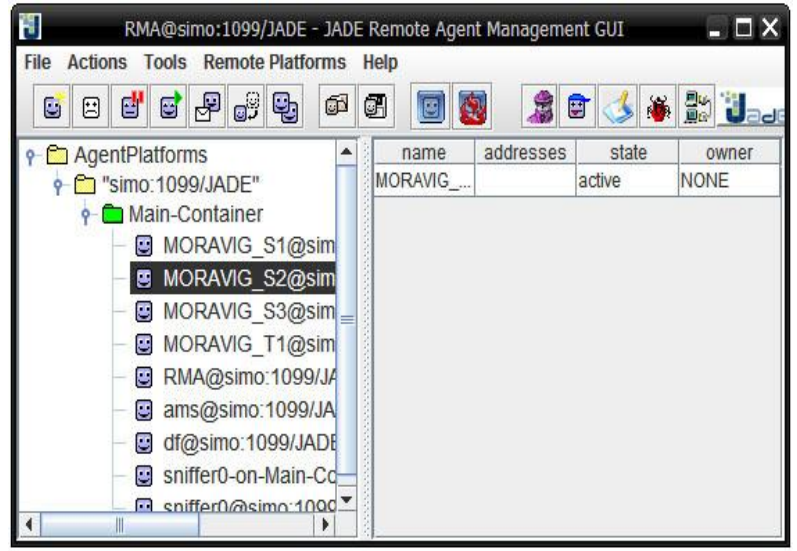

Fig 11: JADE agent platform with all the mobile agents

The JADE remote agent management GUI offers some handy tools for testing and debugging agent applications. For example, the sniffer agent (as shown in figure 12) can trace communications in a group of agents and show the details of ACL message exchanged. Together, these tools provide a powerful and convenient way to test and debug the prototype system.

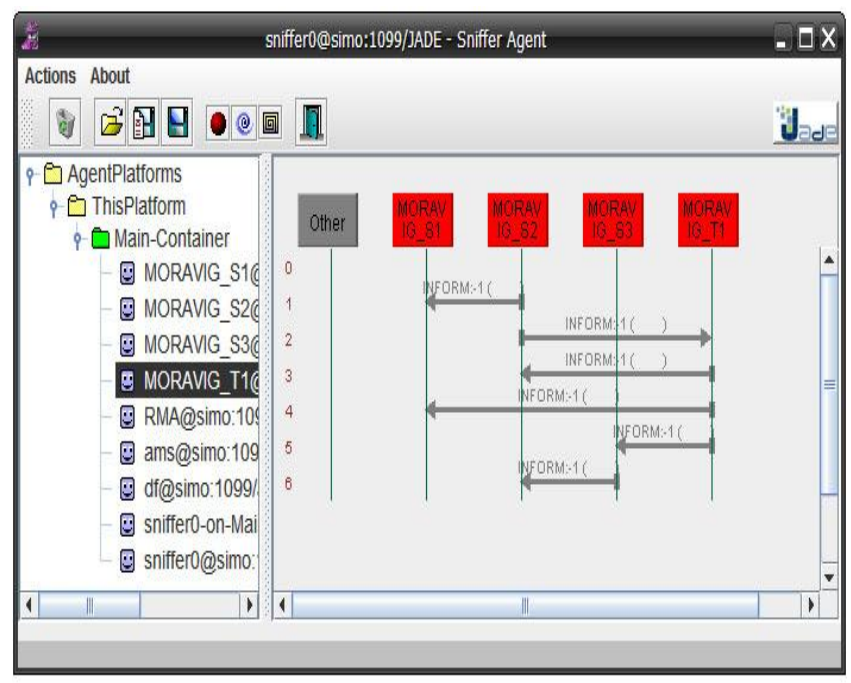

Fig 12: An example of a sequence diagram in JADE using ACL as agent communication language

\section{CONCLUSION AND FUTURE WORK}

In this article, we have shown that (1) Cloud computing must support e-learning and mobile-learning such as LaaS (Learning as a Service),(2) Cloud infrastructures can offer an ideal platform for implementing Massive Open Online Courses (MOOCs) and, (3) Multi-Agents technology is becoming more and more important in MOOCs.

In this context, we have developed a companion agent called MORAVIG (MORoccan Android VIrtual Guide), which can (1) provide assistance and help for students and teachers to apply project management process in Project Mobile eLearning (PMeL) session, (2) facilitate monitoring and supervising multiple projects by teachers at the same time in Massive Open Online Courses (MOOCs).

In the development of this Project Mobile e-Learning Agent, JADE-LEAP ANDROID has been successfully used to implement MORAVIG. For specific tasks, it is very useful to have an agent platform on the mobile device itself. The viability of the system is proven in the implementation details of a prototype following Android development guidelines and a MASE methodology tailored for the JADE development framework.

The future work consists to experiment and validate MORAVIG in final study project for the students in higher education. The main goal is to know, at what level MORAVIG can give assistance and help for students and teachers to apply project management process in PBL session. Moreover, at what level it can facilitate monitoring and supervising multiple projects at same time in Massive Open Online Courses (MOOCs) for example.

\section{REFERENCES}

[1] M. Bousmah, N. Elkamoun, A. Berraissoul. 2006 "Online Method and Environment for Elaborate the Project-Based Learning Specifications in Higher Education", Proceedings of the 6th IEEE International Conference on Advanced Learning Technologies, ICALT 2006, 5-7 July 2006, Kerkrade, The Netherlands. IEEE Computer Society 2006 BibTeX.

[2] M. Bousmah, N. Elkamoun. 2014. " Feedback of Project Management Approach in Higher Education Science" 26th Symposium of the European ADMEE 15-16-17 January 2014 in Marrakech, Morocco.

[3] Fiona M. Hollands, Devayani Tirthali. 2014. " MOOCs: Expectations and Reality", Full Report, Center for Benefit-Cost Studies of Education Teachers College, Columbia University, May 2014.

[4] NIST, National Institute of Standards and Technology. 2013. " Cloud Computing Standards Roadmap Working Group", U. S. Department of Commerce, Reports on Computer Systems Technology, July 2013

[5] Nungki Selviandro, Zainal Arifin Hasibuan. 2013. "Cloud-Based E-Learning: A Proposed Model and Benefits by Using E-Learning Based on Cloud Computing for Educational Institution", Springer Information and Communication Technology, Volume 7804, 2013, pp 192-201

[6] Md. Anwar Hossain Masud, Xiaodi Huang. 2012. "An Elearning System Architecture based on Cloud Computing", International Journal of Social and Human Sciences 04/2012; 6 .

[7] E. Tuncay. 2010. "Effective use of Cloud computing in educational institutions," Procedia Social Behavioral Sciences, p. 938-942, 2010.

[8] Y. Zhongze. 2010. "The basic principles of cloud computing and its impact on education", Satellite TV and Broadband Multimedia, 2010.6, pp.67-70.

[9] Z. Chengyun. 2010. "Cloud Security: The security risks of cloud computing, models and strategies", Programmer, May.2010, pp.71-73.Bowman, M., Debray, S. K., and Peterson, L. L. 1993. Reasoning about naming systems.

[10] Class Central. 2015. https://www.classcentral.com/report/moocs-stats-and-trends-2014/ [Accessed 4th February 2015]

[11] Dhawal Shah. 2014. " A Review of MOOC Stats and Trends in 2014", available from https://www.classcentral.com/report/moocs-stats-and-trends-2014/ [Accessed 4th February 2015] 
[12] Usnews. 2015. US News \& World Report rankings, available from http://www.usnews.com/rankings [Accessed 4th February 2015

[13] Gaurav Jindal, Mayank JainA. 2012. "Comparative Study of Mobile Phone's Operating Systems", International Journal of Computer Applications \& Information Technology Vol. I, Issue III, November 2012 (ISSN: 2278-7720)

[14] Rustain, A.M. \& Estes, W.E. 1995. "What every engineer should know about project management", Marcel Dekker, 1995.

[15] Clifford F. Gray \& Erik W. Larson. 2006. " Project Management the Managerial Process". (3rd ed.) McGraw Hill. pg. 6

[16] Wooldridge Michael and Nick Jennings. 1995. "Intelligent Agents: Theory and Practice", Cambridge University Press , 1995.

[17] Najib EL KAMOUN, Mohammed BOUSMAH, Abdelhak AQQAL. 2011. "Virtual Environment Online for the Project-Based Learning Session ", Cyber Journals: Multidisciplinary Journals in Science and Technology, Journal of Selected Areas in Software Engineering (JSSE), January Edition, 2011.
[18] Arnon Sturm. 2005. "Multiagent Systems Engineering (MaSE) - An Introduction". 12-Jul-2005, available from http://www.pa.icar.cnr.it/cossentino/al3tf1/docs/mase4ag entlink.pdf [Accessed 4th February 2015]

[19] Rimassa G., Bellifemine F., Poggi A.1999. JADE - A FIPA Compliant Agent Framework, PMAA 99, p. 97108, Londres, Avril 1999.

[20] Lee L. C., Ndumu D. T., Nwana H. S.1998. ZEUS: An Advanced Tool-Kit for Engineering Distributed MultiAgent Systems. In Proceedings of the Practical Application of Intelligent Agents and Multi-Agent Systems, p.377-392, Londres.

[21] O. Gutknecht, J.Ferber \& F. Michel, RR, 2000. MadKit: une plateforme multi-agent générique, Rapport interne,Laboratoire LIRMM, Université Montpellier II, Mai 2000

[22] AgentBuilder U.G.2004. An Integrated Toolkit for Constructing Intelligent Sofware Agents, AgentBuilder, User's Guide, Avril 2004, available from http://www.agentbuilder.com/Documentation/UsersGuid e-v1.4.pdf [Accessed 4th February 2015]

[23] FIPA Specifications. 2000. available from http://www.fipa.org/repository/fipa2000.php3 [Accessed 4th February 2015] 